\title{
El taller y la integración curricular. Reflexiones sobre la herencia y el porvenir en el aula universitaria ${ }^{1}$
}

\author{
Irene Marina Macera² \\ Universidad Abierta Interamericana, Rosario, Argentina ${ }^{3}$ \\ irene.macera@uai.edu.ar
}

1 Artículo de reflexión.

2 Doctora en Humanidades y Artes con mención en Ciencias de la Educación, Universidad Nacional de Rosario — UNR — . Licenciada y profesora de Ciencias de la Educación — UNR—.

3 Directora del Departamento de Orientación Pedagógica de la Universidad Abierta interamericana - UAI-, sede Rosario. 


\title{
El taller y la integración curricular \\ Reflexiones sobre la herencia y el porvenir en el aula universitaria
}

\section{Resumen}

El artículo que aquí se presenta contiene reflexiones pedagógicas en torno a experiencias de integración que se suscitan al interior de la carrera de Arquitectura de la Universidad Abierta Interamericana - UAI-, sede Rosario. Dos líneas de trabajo interesa resaltar en términos pedagógicos: proyectos de integración centrados en un pensamiento acerca de los lenguajes de la arquitectura y sus modos de expresión y transmisión, por un lado, y, por el otro, propuestas de integración curricular caracterizadas por producir experiencias pedagógicas que ocasionen rupturas en los ritmos habituales del aula. Se presentarán para ello registros de observación de clase y documentos internos institucionales. Consideramos que estas reflexiones sobre la experiencia permitirán alcanzar hipótesis acerca de la transmisión propia de la época que nos toca vivir.

Palabras clave: currículum, taller, prácticas de integración.

\section{The Workshop and Curricular Integration. Reflections on the Heritage and the Future in the University Classroom}

\begin{abstract}
This article contains pedagogical reflections on the experiences of integration that arise within the Architecture program of the Open University Inter-American -, Rosario headquarters. Two frameworks should be highlighted in pedagogical terms: integration projects centered on an approach to the languages of architecture and their modes of expression and transmission, on the one hand, and, on the other, proposals for curricular integration characterized by producing pedagogical experiences that cause ruptures in the habitual rhythms of the classroom. Class observation records and institutional internal documents will be submitted to illustrate the results. We understand that these reflections on the experience will allow to reach hypotheses about transmission, typical of the time that we live in.
\end{abstract}

Keywords: Curriculum, Workshop, Integration Practices.

\section{O workshop e a integração curricular. Reflexões sobre a herança e o porvenir na sala universitária}

\section{Resumo}

O artigo que aqui se apresenta contém reflexões pedagógicas em torno de experiências de integração que se suscitam ao interior da carreira de Arquitectura da Universidad Abierta Interamericana -UAI-, sede Rosario. Duas linhas de trabalho interessa realçar em termos pedagógicos: projetos de integração centrados num pensamento a respeito das linguagens da arquitectura e seus modos de expressão e transmissão, por um lado e, pelo outro, propostas de integração curricular caracterizadas por produzir experiências pedagógicas que ocasionem rupturas nos ritmos habituais da sala. Se apresentarão para isso registros de observação de classe e documentos internos institucionais. Entendemos que estas reflexões sobre a experiência permitirão atingir hipótese a respeito da transmissão, própria da época que nos toca viver.

Palavras chave: Currículum, oficina (workshop), práticas de integração. 


\section{Introducción}

El artículo que aquí se presenta contiene reflexiones pedagógicas en torno a experiencias de integración que se suscitan al interior de la carrera de Arquitectura de la Universidad Abierta Interamericana — UAl-, sede Rosario. Nos referiremos a experiencias de integración elaboradas desde el 2013 hasta la fecha. En estos años, hay dos líneas de trabajo que son relevantes resaltar en términos pedagógicos. Un primer ciclo que estuvo signado por un pensamiento acerca de los lenguajes de la arquitectura. El pensamiento pedagógico que suscitó este período estuvo marcado, quizás, por lo que dio origen a esta escritura, esto es, la transmisión de un oficio/profesión —la de diseñar- y las herramientas con las que el conocimiento se transmite, los ámbitos que se precisan y las relaciones que se producen. $Y$ un segundo ciclo signado por lo metodológico, por producir experiencias pedagógicas que ocasionen rupturas en los ritmos habituales del aula, en el que la intencionalidad educativa busca caotizar, transgredir, de-construir, borrar los espacios y tiempos de la clase.

Consideramos que este tipo de propuestas son posibles en tanto las clases de taller que forman parte de la rutina y el paisaje de la carrera ya contienen en sí mismas elementos que permiten pensarlas. Es por ello que resulta relevante presentar el aula-taller como punto de partida hacia los proyectos de integración. Entendemos que reflexionar acerca de estas experiencias pedagógicas bajo la lente del taller, en cuanto espacio de formación y producción, nos permite alcanzar hipótesis acerca de la transmisión propias de la época que nos toca vivir.

Es preciso aclarar aquí que los proyectos de integración en la UAl se enmarcan en una concepción curricular que busca superar la estructura de colección mosaica (Álvarez \& DeVincenzi, 2006), tradicional del ámbito universitario en general. Desde el año 2001 la institución inicia un proceso de cambio en el diseño de los planes de estudio, resaltando los problemas que preocupan a la sociedad, y definiendo así ejes socioprofesionales que sustenten cada diseño curricular.

Los ejes socioprofesionales constituyen, entonces, estructuras curriculares que tienen el fin de promover la integración de los contenidos en torno a las necesidades sociales identificadas en las prácticas profesionales (Documento Interno UAl, 2009). Con los mismos se busca promover la integración curricular y, para ello, se designan entre los profesores de cada carrera «coordinadores de eje» que se encargan, junto al director de carrera, de gestionar dicha integración curricular.

En la carrera de Arquitectura, las coordinaciones de ejes socioprofesionales asumen integraciones curriculares horizontales y verticales; las problemáticas a trabajar, muchas veces, surgen en el seno de los mismos claustros, al calor del 
intercambio entre profesores. Esto permite cruces disciplinares que no sólo responden a un mismo estadio de formación —integración horizontal-, sino también a la integración de la diversificación de niveles de complejidad en distintos estadios integración vertical一, permitiendo experiencias de aprendizaje entre pares, y ya no únicamente con los profesores.

En relación con la metodología, se utilizarán registros de observación de clase para ilustrar las escenas cotidianas del aula-taller; documentos internos para mapear la organización institucional y comprender las definiciones y formalidades de los proyectos de integración ${ }^{4}$.

\section{El aula-taller, lo heredado}

[...] la verdad es inseparable de las prácticas y de los procedimientos.

(Deleuze, 2013)

Es a partir del taller que se produce un abanico de singularidades en la formación del arquitecto que comienza en esta expresión del pensamiento que es el dibujo, en el que se involucra el cuerpo y diversas herramientas analógicas y digitales. Teniendo en cuenta ello, cuando nos referimos al aula-taller aludimos sobre todo a esta transmisión de conocimientos explícitos e implícitos que ocurren cuando el maestro muestra-demuestra el modo en que se hacen las cosas. Se trata de una modalidad de transmisión de saberes asociados directamente a la construcción de un objeto-proyecto.

En este sentido, con el propósito de comprender mejor este mecanismo y lo que allí se pone en juego, abordaremos las conceptualizaciones de Richard Sennet quien, como buen defensor del pragmatismo, se interesa por demostrar que en toda práctica o en todo hacer se expresa la ética.

4 Este escrito es fruto de observaciones de clase, conversaciones formales e informales con los docentes de la carrera, reuniones de claustro, capacitaciones y registros de documentos internos que se producen desde el Departamento de Orientación Pedagógica —DOP—, una unidad de asesoramiento de los distintos órganos de conducción de la Universidad en lo atinente al desarrollo y capacitación pedagógica del personal docente. Para ello, cuenta con un equipo de pedagogos(as) que acompaña el funcionamiento de cada una de las carreras a través de observaciones de clase y propuestas de coloquios, talleres o encuentros de trabajo acerca de los procesos de enseñanza y aprendizaje. En este orden de ideas, el DOP atiende consultas de docentes, directores, decanos y participa del diseño y desarrollo de la Escuela de Auxiliares en Docencia. (Res. C.S. ${ }^{\circ}$. 4527/15).

Para un buen funcionamiento, el DOP necesita establecer relaciones colaborativas con cada una de las carreras y las mismas asumen rasgos específicos atendiendo a la singularidad del área disciplinar y de gestión. En el caso que aquí ocupa, entre la carrera de Arquitectura y el DOP se gestó un pensamiento pedagógico en torno a preguntas que inquietaban al claustro y al equipo de gestión, expresadas en los proyectos de integración. 
El movimiento del hacer-pensar que todo profesional de oficio conoce ha sido motivo de disonancias y distinciones en la organización de la ciudad. Ya nos recuerda Rancière (2013) que tanto el artesano como el campesino en las ciudades clásicas eran vistos como personas dedicadas a su trabajo que carecían de tiempo para el pensamiento. Se comienza de ese modo a crear una grieta entre el pensar y el hacer $y$, de allí en adelante, este debate sigue abierto. Recuperar la figura del artesano y su formación en el taller es un modo de comprender las formas y los alcances que adquiere la idea de "aprender haciendo» que se encuentran en las prácticas transmitidas de generación en generación por ciertos oficios y profesiones.

Artesano es aquel que se dedica a hacer bien su trabajo por el simple hecho de hacerlo bien, la artesanía es una actividad formadora, es compromiso, afirma Sennet (2009). Cada época hereda y ensaya formas propias de artesanos y talleres. Es así que en el siglo Xxı nos encontramos desde el viejo oficio de carpintero hasta el investigador de laboratorio, el músico en su orquesta o los técnicos de Linux (Sennet, 2009).

El interés aquí por recuperar esta figura no lo es tanto por la figura en sí, sino por sus modos de producción: el taller. Así las cosas, los orígenes del mismo se asemejan también al estudio del artista en cuanto ambos eran espacios llenos de asistentes y aprendices. La diferencia importante entre ambos era el valor otorgado a la originalidad del trabajo. Mientras que el arte tiene un agente orientador, la artesanía tiene un agente colectivo; mientras que el arte se vuelca hacia el interior, la artesanía se vuelca hacia su comunidad; el arte llama la atención sobre la pieza/ trabajo único mientras que la artesanía se pliega hacia una práctica anónima colectiva y continuada; el trabajo del artesano es impersonal, aun cuando haya obras con firmas de autor, y el trabajo del artista es único. Sin embargo, el estudio del artista del Renacimiento no se diferenciaba del taller medieval ni del laboratorio científico moderno. Atender a este vértice en el que se encuentran el taller del artesano y el estudio del artista, lo colectivo y lo original, lo exterior e interior en la formación del arquitecto, es crucial dado que el aula-taller aglutina ambas prácticas y sostiene esta ambigüedad entre la firma de autor y el trabajo colectivo.

Los talleres, hoy como ayer, han sido y son un factor de cohesión social mediante rituales de trabajo, sea el de compartir una taza de té, sea el del desfile de la ciudad; mediante la tutoría, sea la formal paternidad subrogada del medioevo, sea el asesoramiento informal en el lugar de trabajo; o mediante el hecho de compartir cara a cara la información. (Sennet, 2009, p. 96).

El aula-taller en UAl es un espacio organizado por mesas-tableros donde pueden agruparse entre dos y cuatro personas; se disponen de computadoras utilizadas para bajar archivos o realizar búsquedas en la web; los pizarrones suelen ser fijos, aunque según el aula pueden trasladarse; $y$, asimismo es posible hacer uso del proyector. 
La franja horaria suele ser extensa y puede ocupar toda una mañana, toda una tarde o toda la jornada nocturna. Estos espacios-tiempo permiten que acontezcan diferentes ritmos de producción, diferentes ritmos en las relaciones, en los intercambios $y$, sobre todo, es un periodo en el que el estudiante tiene tiempo de ponerse a trabajar y el docente de observar ese trabajo. Este gesto, que puede parecer una obviedad pero que no lo es; ya advierte Carlino (2005) que en el aula universitaria tradicional el que más trabaja es el docente, dado que para preparar su clase estudia, selecciona bibliografía, realiza recortes teóricos, asume posiciones, en tanto que el alumno queda olvidado, sin preverse actividades-tareas que también lo pongan a producir.

Decíamos entonces que el tiempo del aula-taller es un tiempo para producir, intercambiar, observar, imitar, investigar, crear con el profesor pero también entre pares. El trabajo con otros forma parte de la atmósfera del aula-taller, por tanto, aunque el trabajo pueda ser individual siempre hay otro, un posible interlocutor, interventor del diseño propio y viceversa.

El tiempo con el otro en el taller es un tiempo distendido que permite introducir distracciones, pausas, un continuo difuso entre el trabajo, la charla, las anécdotas de la vida fuera del aula.

Los(as) docentes asumen una performance, en el sentido en que es una acción que contiene la improvisación, que tiene un sentido estético y busca la provocación en los destinatarios de la misma. Dado que tienen que convocar a embarcarse en proyectos, los(as) docentes no sólo deben planificar su clase en lo referente a contenidos visuales y bibliográficos, sino pensar la forma en que se realizan sus presentaciones, los materiales y herramientas que la acompañarán, pues no sólo se transmite una consigna sino, sobre todo, el deseo de embarcarse en un nuevo proyecto.

[...] Comienza la clase y el profesor acompañado de recursos audiovisuales presenta una obra. Los alumnos están en ronda-semicírculo. Se analiza la obra con fotografías, a partir del eje del «contexto». La selección visual tiene que ver con ello también, no se muestran fotos de interiores. Se agudiza la mirada, la escucha y la oralidad sobre el eje de trabajo propuesto para el análisis. Se comparten también otras fotografías y el docente explica las relaciones que él encontró entre estas y la obra, la importancia del contexto que hay en ellas. La oralidad del docente está teñida de recursos literarios, y no sólo teóricos, con fragmentos variados, plurales, que incluyen historias de vida, datos geográficos, relatos estéticos, etc. (Observación de clase «Problemática de la Arquitectura Contemporánea», tercer año 2015).

Podemos observar la preocupación tácita por la forma que lleva intrínseco el contenido, sin escisión, del mismo modo que entre el hacer y el pensar. En la producción en taller lo que se expresa es la forma y el espacio del taller no hace otra cosa que mostrar, hacer visible ese proceso. 
Con respecto a las relaciones con la autoridad, en el taller de la Edad Media la autoridad tenía tres niveles de jerarquía: maestro, oficiales, aprendices. El aprendiz estaba en periodo de formación durante siete años. Al finalizar ese tiempo, presentaba una obra, fruto de todo ese periodo, para demostrar las habilidades elementales que había adquirido. Así se recibía de oficial. Para llegar a ser maestro debía trabajar de cinco a diez años más y presentar una obra maestra superior (Sennet, 2009). Llegar a ser maestro respondía a la adquisición de habilidades y esto era inseparable de la ética.

Vemos cómo esta idea de presentar en una obra la adquisición de las habilidades es un recurso cada vez más vigente, esto es, convocar al estudiante a producir y, en ese proceso, que él mismo vaya encontrando las respuestas y soluciones a sus errores hasta alcanzar un producto final que se pretende contenga la superación de los mismos, en el que el profesor estará guiando, monitoreando, interrogando, observando ese proceso. A continuación, presentamos citas de observaciones de clase de las asignaturas Introducción al Proyecto, Proyecto IV, Representación Arquitectónica, Proyecto III:

[...] Se observa toda la clase. La misma consiste en el cierre de trabajos. Los estudiantes preparan su presentación, tanto gráfica como oral. En esta preparación, consultan al docente y este se muestra receptivo a comentarios, dudas, etc. En la presentación, los estudiantes muestran sus dibujos y explican el proceso que los llevo a ellos vinculándolos con los objetivos que había planteado el profesor para los mismos. Es allí donde observamos un proceso autoevaluativo, ya que los mismos estudiantes realizan una reflexión al respecto. También hay una presentación de trabajo grupal, que es transversal a este proceso, que consiste en la presentación por parte de un grupo de estudiantes de una búsqueda exploratoria por las obras de un arquitecto. En ambos momentos hay gran participación por parte de los estudiantes y un desenvolvimiento del docente que amplía los temas y los vuelve complejos en sus devoluciones... (Observación de clase de «Introducción al proyecto», primer año).

Se observa una clase de enchinchada. Ni bien llegan los estudiantes en grupo y preparan la exposición de sus trabajos. Cuando se comienza a presentar cada uno, el profesor inaugura la enchinchada recuperando ciertas consignas de trabajo como son la idea de pensar la arquitectura para la vida, para el uso cotidiano, vinculada a las actividades de los hombres. A partir de allí se realizan las presentaciones donde el foco de las devoluciones corresponde a estas consignas mencionadas [...] Se considera que las devoluciones están acordes con el planteo que realiza el profesor, que posibilitan la reflexión de los estudiantes y la autoevaluación. (Observación de clase de «Proyecto IV», cuarto año).

La clase está dividida en dos momentos: de exposición grupal de indagaciones exploratorias acerca de obras arquitectónicas y de trabajo en taller.

En ambos se contempla el proceso de producción individual y grupal, brindando herramientas para la mayor autonomía del mismo por parte de los estudiantes. Es por ello que en ambos momentos de la clase son los estudiantes los que la protagonizan 
y el rol del docente se vincula a orientar y brindar herramientas para cumplir con este logro autónomo y de desarrollo cognitivo de los estudiantes. (Observación de clase de «Representación arquitectónica l», primer año).

Cada alumno individualmente prepara su enchinchada, con maqueta, proyecto final trabajado durante la última parte del año y carpeta sintetizadora de los proyectos realizados. Se trata de fundamentar decisiones, explicar el proyecto y que los profesores intervengan con preguntas, comentarios y correcciones. (Observación de clase de «Proyecto III», tercer año).

La autoridad del maestro en el taller se ancla en su experiencia, en la duración en una práctica y su pericia. Este maestro con autoridad forma a los aprendices en el desarrollo de sus habilidades y lo hace produciendo. La habilidad que desarrolla se da a través de una práctica de formación, de la observación, imitación y repetición, logrando niveles cada vez más complejos. Volver una y otra vez a una acción permite la autocrítica y, en cada repetición, lo que repite cambia de contenido. A medida que el trabajo se vuelve más complejo, la habilidad mejora su sintonía con el problema y se separa de esa primera actividad mecánica para dar lugar a un pensamiento más profundo (Sennet, 2009).

[...] en un laboratorio es fácil introducir al novato en materia de procedimientos, mucho más difícil es para un científico transmitir la capacidad para indagar la presencia de nuevos problemas en el curso de la solución o para explicar la intuición surgida de la experiencia. (Sennet, 2009, p. 97).

La dificultad en la transferencia de conocimientos ocurre tanto en los laboratorios como en los estudios de artistas. Esta tiene que ver con hacer de la expresión de los discípulos un constante objeto de análisis y refinamiento: utilizar diferentes recursos para aumentar la expresividad individual. Sabemos que el aprendizaje por excelencia en taller es el de la imitación, la repetición y que desde allí se van logrando formas más complejas de interpretar los procedimientos y comprender de forma más amplia cómo utilizar lo que se sabe. Conocemos que este aprendizaje, entonces, se trata, principalmente, de la transferencia de un conocimiento tácito, no verbal, sin codificar en palabras, que versa sobre los mil movimientos cotidianos que se agregan a una práctica (Sennet, 2009).

Cuando el arquitecto-profesor examina los proyectos que elaboran sus alumnosaprendices, el modo en que analiza, piensa y muestra cómo piensa a través de la mano en contacto con el lápiz que, a su vez, no se despega de la hoja, que dibuja, garabatea, está transfiriendo conocimientos tácitos, está transfiriendo modos en que hacer y pensar son una sola y misma cosa. Esto último es una de las adquisiciones necesarias para todo futuro arquitecto. Justamente por ello, tal vez el momento donde más se observa la transmisión propia del taller es cuando el(la) profesor(a) se sienta junto a los estudiantes y revisa, supervisa sus producciones, haciendo preguntas, hipotetizando razones, trayendo imágenes, antecedentes, todo esto en tanto su mano 
dialoga con el proyecto a través de trazos, bocetos.

Aquí es preciso detenerse en los proyectos de integración de la carrera dado que en ellas encontramos signos de este tipo de búsquedas que hace el maestro hacia sus estudiantes; búsquedas novedosas para aumentar la expresividad individual a partir del ofrecimiento de experiencias de aprendizaje diferentes.

En el año 2013, se propuso como actividad integradora instalar en todos los alumnos-aprendices el uso de un cuaderno único de bocetos, ideas, etc. Todos tenían el mismo cuaderno, las mismas medidas, el mismo color. Pero cada cuaderno era único. Comunidad y originalidad. Piensas y haces, dibujas y haces parece ser la fórmula que se desprende de la experiencia. La mano transmite el pensamiento del arquitecto. Se requiere lograr una circularidad entre dibujar y hacer. «El hecho de dibujar ladrillos a mano, por tedioso que sea, instiga al dibujante a pensar en su materialidad, a hacerse cargo de su solidez» (Sennet, 2009, p. 57).

La preocupación de los profesores en ese momento se centró en recuperar prácticas y objetos que en su propia biografía de formación habían estado presentes y que continuaban siendo herramientas insustituibles de pensamiento y creación. Si cada uno de ellos tuviera que decir dónde, cómo y cuándo el cuaderno se transformó en una extensión de su cuerpo, no sabrían afirmarlo. Ese conocimiento tácito, esa transferencia por imitación, en un mundo de objetos tecnológicos, fue concebida por este grupo de profesores como algo bajo amenaza. Un taller bien administrado debe equilibrar el conocimiento tácito con el explícito. La búsqueda del boceto que proponían los profesores seguramente advertía que algo del conocimiento tácito que pasa de generación en generación se les estaba escurriendo y era preciso recuperarlo.

Este proyecto fue el inicio de una serie de propuestas acerca de los lenguajes de la arquitectura. Las preguntas que rondaban se vinculaban a cómo se expresa el pensamiento mediante el boceto, el dibujo, y cuál es el lugar de la palabra y la transmisión. Así lo expresábamos en aquel momento:

Muchas veces solemos confundir el acto de pensamiento con el proceso intelectual traducido en producción teórica. Una hipótesis puede ser la gran influencia enciclopédica positivista de la ciencia en la cultura, de modo tal que se instala como sentido común.

Sin embargo, reflexionando sobre el gran arco de saberes y prácticas, entendemos que el acto de pensamiento es un proceso intelectual que tiene múltiples formas de traducción.

Se piensa tocando un instrumento, se piensa entrenando un deporte, se piensa dibujando, se piensa modelizando. El cuerpo manifiesta de diferentes maneras nuestro pensar. Por eso nos atrevemos a decir que existen distintos lenguajes del 
pensamiento que, generalmente, coexisten en cada uno de nosotros, pero donde alguno de estos es más promovido por el deseo.

Entonces, si decimos que también se piensa haciendo, que también el cuerpo piensa, que hay distintos lenguajes de pensamiento, los invitamos a responder juntos: ¿cuáles son los lenguajes de la arquitectura?, y, ¿cómo se transmiten?

Estas preguntas, asimismo, nos conducen a reflexionar sobre las interconexiones existentes entre la palabra, la cultura y el contexto de la arquitectura; entre el proceso imaginado, los medios y los recursos, las resultantes proyectadas y los contextos de producción. (Documento interno UAI, «Convocatoria de la carrera de Arquitectura a la Escuela de Auxiliares»).

Esta convocatoria, se daba en el marco de un proceso de proyectos de integración, diseñados y propuestos por la coordinación de ejes socioprofesionales, titulado «la gráfica como lenguaje», en el que se expresaba:

[...] la arquitectura es concebida desde el plan de estudio de la carrera como un saber complejo que requiere de multiplicidad de visiones y perspectivas que demanda la formación de un arquitecto no sólo en lo técnico-científico, sino en lo artístico proyectual, capaz de comprometerse con el medio social y ambiental. Desde esa perspectiva nos interesa generar instancias de reflexión y producción interdisciplinaria sobre distintos aspectos de su hacer profesional. En este sentido, y durante el año 2013, la tarea se centrará en la gráfica como aspecto transversal a ser trabajado en las asignaturas comprometidas en el presente proyecto.

La gráfica dentro del campo de la arquitectura es una herramienta que permite pensar, analizar e interpretar. Es un recurso tanto de creación como de expresión y desde este lugar se constituye en «lenguaje» que viabiliza el acercamiento y la comunicación dentro del mundo de la arquitectura.

La naturalización en el manejo del código gráfico en el estudiante de arquitectura representa un aspecto formativo fundamental que favorecerá la incorporación del dibujo como proceso de pensamiento, como medio de representación de la realidad y como instrumento de prefiguración, cuya génesis es totalmente independiente de las nuevas tecnologías. (Ciccero \& Peralta, 2015).

Todo el desarrollo hecho hasta aquí no ha efectuado otra cosa que envolver esta primera inquietud de pensamiento: la expresión del pensar en la arquitectura y la complejidad de su transmisión. Y ello se ha llevado a cabo poniendo en relación prácticas presentes con sus antecesoras, resaltando que siempre en la transmisión de un oficio estuvieron presentes potentes categorías pedagógicas para pensar las instituciones de formación. 
La preocupación por el lugar productivo del estudiante en su propio proceso de formación la encontramos explícitamente, por citar tan sólo un caso, en Benjamin (1994). Ya en las primeras décadas del siglo xx, cuando planteaba la necesidad urgente de que la pedagogía moderna creara un espacio adecuado para que la cultura se autodesarrolle, criticaba la mentalidad escolar de los estudiantes, profundizada por la universidad cada vez que se apelaba a la atención mecánica, y sostenía que la organización de la universidad ya no se hallaba en función de la productividad de sus alumnos, tal como había sido el espíritu de sus fundadores.

\section{El aula-taller, lo por-venir}

Habiendo mapeado el presente en relación con el pasado, el taller de hoy y el taller de ayer, nos ocupará ahora mapear el presente en función de lo por-venir o quizás, más precisamente, en lo que está ocurriendo a la luz de nuevas conceptualizaciones que piensan el futuro de la formación universitaria, el taller y el trabajo colaborativo, los saberes distribuidos a través de experiencias de integración curricular.

Para tal fin, se presentará un proyecto de integración iniciado, que continúa vigente, en el que se resalta la intencionalidad educativa de introducir el "caos» en la organización de la cursada para permitir otros ritmos de aprendizaje, otras relaciones de autoridad y autonomía; por ello, nos referimos a la figura del aula caótica como experiencia que dialoga con los presupuestos acerca de los jóvenes y la distribución de los saberes.

Resulta interesante recuperar las reflexiones de un filósofo que, en tanto era profesor de filosofía en una universidad de Francia, Michel Serres, se pregunta por quiénes son, qué tratan los jóvenes que asisten a sus clases. Allí advierte que se asiste a la universidad del mismo modo que en el siglo pasado aun cuando todos los ciudadanos del mundo insertos en las Ilamadas «sociedades del conocimiento» asumimos un cambio de época sin precedentes. Nadie duda que las tecnologías de la información y la comunicación permitan que las nuevas generaciones manejen diversas informaciones simultáneamente, pareciera también que nadie duda de que ello produce nuevos modos de acceder y vincularse con los conocimientos:

[...] observemos a Pulgarcita manipular un teléfono celular y dominar con sus pulgares las teclas, los juegos o los buscadores: despliega sin vacilar un campo cognitivo que una parte de la cultura anterior, la de las ciencias y las letras, dejó largo tiempo en barbecho y que se puede llamar procedimental. [...] estos procedimientos atraviesan hoy el saber y las técnicas. (Serres, 2012, p. 89).

Estas nuevas generaciones acceden a cualquier saber, mientras que antes el saber era celosamente guardado en bibliotecas y disciplinas a las que accedían los estudiosos, profesionales o universitarios. Hoy, en cambio, está en todas partes: 
disponible, objetivado y distribuido. La cabeza de los jóvenes es otra, sostiene Serres (2012), no es más que un recipiente interno para almacenar. La información se almacena en la actualidad en diversos formatos dentro de discos rígidos externos, las propias facultades de las personas también están allí en la medida en que acceder a su utilización les permite activar buscadores e inventar formas de acceso y aproximaciones. La enseñanza de la era de la cognición interna consistió en una oferta que no tenía en cuenta la demanda, el(la) estudiante. Hoy se invierte, es preciso atender a ese murmullo ensordecedor del aula (Serres, 2012, p. 40).

En estas afirmaciones encontramos muchos elementos de trabajo para pensar lo pedagógico en la universidad, incluso en las prácticas que se presentan, en las que hay un movimiento permanente entre docentes y estudiantes para encontrar los modos de interpretar las huellas que lo nuevo señala e inventar prácticas acordes con ello.

Existen numerosas líneas de investigación ocupadas de esta problemática. Desde la literatura con perspectiva psicológica, el eje del aprendizaje ha llevado a contornear el concepto de cognición distribuida, que de alguna manera retoma Serres, en el que lo cultural, los artefactos culturales, se presentan con una relevancia mucho mayor y más amplia sobre el aprender que la otorgadas por las teorías psicológicas hasta el momento. Aquí no profundizaremos en ello, pero sí ponemos de relieve que estas líneas de investigación constituyen búsquedas de comprensión de lo que sucede en las aulas con los jóvenes universitarios y las formas de inventar motivaciones e inspiraciones, teniendo en cuenta lo que ellos mismos traen de su vida cotidiana.

En este sentido, interesa resaltar aquí la idea de aprendizaje colaborativo (Barkley, Cross \& Mayor, 2007) como aquel trabajo en conjunto, con metas de aprendizaje comunes, diseñadas por el propio grupo, que busca un trabajo equitativo entre los miembros. El aprendizaje colaborativo redobla la apuesta del concepto de aprendizaje cooperativo en cuanto le otorga un lugar mucho más tangencial al profesor y el grupo cobra real autonomía con respecto a este, pues entiende que el saber es una construcción social interna por consenso entre los compañeros de un trabajo, por ende, para que el profesor participe debe sumarse como miembro de esa comunidad en busca de la construcción de saber.

Como vemos, la construcción social del aprendizaje interpela fuertemente la autoridad docente, en el taller la cuestión de la autoridad se trata no como algo trascendente sino a partir de la experiencia y la adquisición de habilidades del maestro. Aquí, pareciera darse un paso más, puesto que no se habla ya de la adquisición del saber, sino de una construcción del aprendizaje realizada al interior de un grupo que comparte las mismas metas acerca del conocer. 
El taller y la integración curricular. Reflexiones sobre la herencia y el porvenir en el aula universitaria

La segunda propuesta de integración que presentamos pareciera ir en esta dirección:

Consigna: arquitectura de un fragmento / tectónico 1:20

Se parte de considerar que resulta altamente significativo para la enseñanzaaprendizaje del proyecto la trayectoria desde lo general a lo particular como su inversa, del fragmento a la totalidad. También se insiste en integrar la experiencia proyectual con los conocimientos de las otras áreas de conocimiento que conforman la carrera.

En la reunión de claustro del lunes 30 de mayo se acordó realizar una aproximación tectónica de los proyectos en actual proceso de desarrollo en cada una de las Asignaturas Proyectuales — primero a quinto año, ambos turnos- Para ello, se proyectará y dibujará en escala 1:20 el frente del edificio, total o parcialmente, según sus dimensiones, entendiendo que se trata de un espesor que incluye soportes, cerramientos, envolventes, y demás particularidades técnicas que incluye el proyecto del edificio en cuestión.

Este trabajo formará parte del recorrido curricular de las proyectuales y contará con la asistencia y participación de las restantes asignaturas de la carrera. Para ese fin, se preparará la información siguiente: 1 planta, 1 corte y 1 vista —armados en correspondencia- y se realizará una maqueta. Todo este material será desarrollado en escala 1:20. Interesa que esta representación gráfica, como su modelo, expresen claramente las particularidades materiales proyectadas, evitando la representación genérica o abstracta. Finalmente, el trabajo se presentará acompañado con una memoria descriptiva del sector expuesto.

\section{$[\ldots]$}

Mecánica de trabajo:

La consigna será dirigida desde las Asignaturas Proyectuales, es decir, que los profesores de las mismas serán los responsables de cumplimentar en tiempo y forma lo estipulado para la entrega.

SEMANA INTEGRADA —-semana caótica— ${ }^{5}$ : Se trabajará durante 1 semana completa, de modo integrado, desde todas las asignaturas del mismo nivel curricular. Es decir, proponemos realizar un debate amplio sobre un tema particular de los proyectos en proceso, en este caso, su lógica material, desde todas las asignaturas — tanto teóricas como técnicas-.

5 El agregado en paréntesis es para el presente artículo, no se encuentra consignado en el documento. 
[...] Durante esta semana los alumnos y los profesores podrán concretar encuentros y consultas libremente con las distintas asignaturas que queden involucradas en los trabajos en proceso de proyecto. Por lo tanto, durante esta semana las distintas asignaturas interrumpirán la secuencia programada para dar lugar al trabajo integrado.

¿Qué Hacer para llegar a la semana integrada de modo ordenado y con material producido?

Primero. La Coordinación enviará los enunciados de los ejercicios en desarrollo en las asignaturas proyectuales a todos los profesores de las restantes asignaturas del mismo nivel de cursado, para que todos los profesores intervinientes puedan saber objetivos y temas en proceso y así poder, luego, prever y armar el dictado de su clase en la Semana Integrada. Además, se adjuntará mails de los profesores para poder facilitar los contactos.

Segundo. Dada la temática elegida, la arquitectura de un fragmento, y su desarrollo tectónico, todas las asignaturas deberán preparar material ilustrativo y dedicarán al menos una clase al tema. Para esto se recomienda hacerlo a través de obras de valor significativo para la disciplina, pertenecientes a proyectistas de relieve tanto anteriores como de la actualidad.

Tercero. Producir discusiones y avances de la temática tectónica desde la Asignatura Proyectual para llegar a la Semana Integrada con material ya producido para realizar críticas y formalizar diferentes enchinchadas en todas las asignaturas.

\section{$[\ldots]$}

\section{Evaluación y crítica}

Esto se cumplirá en la segunda o tercera semana de clases, al inicio del segundo cuatrimestre. Por un lado, se evaluarán los trabajos presentados por los alumnos teniendo en cuenta el nivel al que pertenecen. Esta será una instancia conjunta entre docentes y estudiantes. En segundo lugar, los profesores evaluarán la experiencia realizada en un claustro a celebrar luego de las evaluaciones comprometidas (Ciccero \& Andorni, 2016).

Nos importa aquí esta idea de semana integrada, tal como figura en el documento formal y que se nombra aquí como aula caótica. Llama la atención pues busca lanzar al estudiante a una búsqueda propia, a apropiaciones singulares del espacio y los tiempos; durante el aula caótica los profesores están sujetos a las reglas que pongan los estudiantes en función de las necesidades de sus proyectos. 
La carrera de Arquitectura promueve en sus ciclos lectivos irrupciones a la vida cotidiana académica a través de salidas de una o varias jornadas: visitas a espacios de la ciudad o viajes a otras ciudades o países. En este caso, se introdujo el mecanismo de realización de los proyectos de integración cual engranaje de una maquinaria, en el que se propuso suspender una serie de movimientos «rutinizados». Esto se vincula con la concepción de aprendizaje social y comunidades de práctica (Lave \& Wenger, 1991; Wenger, 2001; Lave \& Packer, 2011) según la cual el aprendizaje tiene que ver con la práctica y no con el saber. Se aprende en las comunidades de práctica, y estas forman partes de nuestra vida cotidiana, imperceptibles y diseminadas en todos los aspectos de nuestra vida. Se trata de una concepción mayor y más amplia de lo que significa aprender.

En reflexiones de claustro posteriores, se ha detectado que no se ha logrado todavía que los estudiantes asuman la libertad y autonomía que esta propuesta les ofrece. Esto da cuenta por sobre todas las cosas que el cambio no es sólo de los profesores o las generaciones adultas, sino que asimismo estas jóvenes generaciones, al interior de las instituciones, no encuentran la manera autónoma de moverse; lo cual implica que juntos pensemos cómo lograr nuevas relaciones con la autoridad y el saber.

\section{Conclusiones}

Se ha propuesto en este artículo mapear las experiencias pedagógicas identificando lo heredado y lo por-venir de las prácticas de enseñanza en el ámbito de la arquitectura. Esta línea que intenta analizarse se da entendiendo la complejidad de nuestras sociedades y sus reflejos en el aula universitaria.

Del taller antiguo al taller de la Modernidad tardía, el pasaje reposa en el lugar de la autoridad y la autonomía. Es allí donde entendemos que se «nuclean» las nuevas conceptualizaciones acerca del par enseñar-aprender. En el primero, la autoridad guiaba al aprendiz a través de prácticas de imitación y repetición; en el segundo, las habilidades y saberes deberán ser encontrados autónomamente en la medida en que se construyan procedimientos entre miembros que compartan metas comunes de aprendizaje; es decir, en ese interior hay relaciones de paridad.

Las observaciones de clase y los documentos que se despliegan a lo largo de este escrito dan cuenta de la combinación de todas estas prácticas que, se considera, son las que posibilitan la creación singular y precisa de las prácticas de integración aquí descritas.

Se entiende que desde estas prácticas de integración, que interpelan la transmisión del saber en la universidad, es que pueden trazarse las prácticas por-venir.

Esperamos que la presentación de estas experiencias y reflexiones contribuyan al pensamiento pedagógico universitario que requiere nuestra época. 


\section{Referencias}

Álvarez, S., y Vincenzi, A. (2006). La integración de conocimientos como intencionalidad en la práctica docente. Circular Pedagógica: UAı. Recuperado de http://api.ning.com/files/1 r6Bh8 Y3Qecg77UlalF1 hqarrk8LJww5Lel31X8FzaEqvlzEgdJOEhvo0eugHVkzmbtyr5LBMBqgm8 *oE9U7gu4KQfG5iBQW/CIRCULARPEDAGGICAN12006integracincurricular.pdf

Barkley, E., Cross, P., y Major, C. H. (2007). Técnicas de aprendizaje colaborativo. Manual para el profesorado universitario. Madrid: Ed. Morata.

Benjamin, W. (1994). La metafísica de la juventud. Buenos Aires: Ed. Altaya.

Carli, S. (2012). El estudiante universitario. Hacia una historia del presente de la educación pública. Buenos Aires: Siglo XXI Editores.

Carlino, P. (2005). Escribir, leer y aprender en la universidad Una introducción a la alfabetización académica. Buenos Aires: Fondo de Cultura Económica .

Ciccero, Y., y Andorni, S. (2016). Documento interno ual. Buenos Aires: UAl.

Deleuze, G. (2013). El saber. Curso sobre Foucault. Buenos Aires: Editorial Cactus.

Lave, J., y Packer, M. (2011). Hacia una ontología social del aprendizaje. Revista de Estudios Sociales, (40), 12-22.

Lave, J., y Winger, E. (1991). Situated Learning. Legitimate peripheral participation. New York: Cambridge University Press.

Litwin, E. (2008). El oficio de enseñar. Condiciones y contextos. Buenos Aires: Paidós.

Peralta, V., y Ciccero, Y. (2013). Documento interno uAl. Buenos Aires: UAI.

Pierella, M. P. (2014). La autoridad en la universidad. Vínculos y experiencias entre estudiantes, profesores y saberes. Buenos Aires: Paidós.

Rancière, J. (2013). El filósofo y sus pobres. Buenos Aires: unGs/Inadi.

Sennet, R. (2009). El artesano. Barcelona: Anagrama.

Serres, M. (2013). Pulgarcita. Recuperado de http://aulasvirtuales2.uruguayeduca.edu.uy/

uAl. (2007). Coordinación de los Ejes Profesionales. Buenos Aires: UAI.

Wenger, E. (2001). Comunidades de práctica. Aprendizaje, significado e identidad. Buenos Aires: Paidós.

Recibido: 31 de enero 2017.

Aceptado: 17 de marzo 2017.

Cómo citar: Macera, I.M. (2017). El taller y la integración curricular.

Reflexiones sobre la herencia y el porvenir en el aula universitaria.

Praxis Pedagógica, 21 (79-94). 